\title{
Developmental changes in plasticity, synaptic, glia, and connectivity protein levels in rat medial prefrontal cortex
}

\author{
Margaret Jia, ${ }^{1,2}$ Alessio Travaglia, ${ }^{1,2}$ Gabriella Pollonini, ${ }^{1}$ Giuseppe Fedele, ${ }^{1}$ \\ and Cristina M. Alberini ${ }^{1}$ \\ ${ }^{1}$ Center for Neural Science, New York University, New York, New York 10003, USA
}

\begin{abstract}
The medial prefrontal cortex (mPFC) plays a critical role in complex brain functions including decision-making, integration of emotional, and cognitive aspects in memory processing and memory consolidation. Because relatively little is known about the molecular mechanisms underlying its development, we quantified rat mPFC basal expression levels of sets of plasticity, synaptic, glia, and connectivity proteins at different developmental ages. Specifically, we compared the mPFC of rats at postnatal day 17 (PNI7), when they are still unable to express long-term contextual and spatial memories, to rat $\mathrm{mPFC}$ at PN24, when they have acquired the ability of long-term memory expression and finally to the mPFC of adult rats. We found that, with increased age, there are remarkable and significant decreases in markers of cell activation and significant increases in proteins that mark synaptogenesis and synapse maturation. Furthermore, we found significant changes in structural markers over the ages, suggesting that structural connectivity of the mPFC increases over time. Finally, the substantial biological difference in $\mathrm{mPFC}$ at different ages suggest caution in extrapolating conclusions from brain plasticity studies conducted at different developmental stages.
\end{abstract}

The dorsolateral PFC (dlPFC) in the human brain plays important roles in higher order cognitive functions and disorders. The anatomical connectivity and functions of this region are similar to those of the medial prefrontal cortex (mPFC) of rodents, which have been widely used to investigate mechanistic questions. The mPFC/dIPFC seems to be involved in many higher order functions by regulating decision-making, learning, integration of emotional and cognitive aspects in memory processing, memory consolidation and remote memory retrieval (Frankland and Bontempi 2005; Rushworth et al. 2011; Arnsten et al. 2012; Euston et al. 2012; Squire and Dede 2015). Given these multiple roles as well as anatomical and electrophysiological evidence, it has been proposed that the mPFC serves to compare the present experience with past memories in order to provide a prediction of the most adaptive response (Euston et al. 2012). To accomplish these functions, the mPFC crosstalks to other brain regions, among which the hippocampus is a most important one. Evidence indicates that the PFC and hippocampus are functionally coupled via oscillatory synchrony that reflects bidirectional flow of information (Hyman et al. 2011; Penagos et al. 2017). In fact, both hippocampus and $\mathrm{mPFC}$ have a critical role in memory consolidation, the process that over time strengthens and stabilizes an initially labile memory representation (Frankland and Bontempi 2005; Euston et al. 2012; Giustino and Maren 2018). This hippocampal-mPFC concerted action has been found in many types of memories, including emotional and neutral, aversive and appetitive, spatial, contextual, and social. Both regions seem to be necessary and operate as a system that uses the current context of experience to retrieve relevant memories (Eichenbaum 2017). The mPFC is also critically involved in retrieval-induced memory strengthening

\footnotetext{
${ }^{2}$ These authors contributed equally to this work. Corresponding author: ca60@nyu.edu

Article is online at http://www.learnmem.org/cgi/doi/10.1101/lm.047753.118.
}

(Ye et al. 2017), which occurs via a restabilization process known as reconsolidation that engages, in addition to the mPFC per se, also other brain regions, such as the hippocampus and the basolateral amygdala (BLA).

Furthermore, the PFC has been implicated in the etiology of numerous neuropsychiatric disorders, particularly neurodevelopmental disorders including intellectual disability, autism spectrum disorders, attention deficit hyperactivity disorder, and schizophrenia (Schubert et al. 2015). Given the importance of the mPFC in higher order cognitive functions and memory processes as well as in brain diseases, particularly in neurodevelopmental diseases, it is surprising that relatively little has been systematically investigated about cellular and molecular biological mechanisms underlying its development and/or maturation of its functional responses. A few studies have carried out proteomic analyses on whole mouse mPFC protein fraction (Laeremans et al. 2013; Gonzalez-Lozano et al. 2016; Agoglia et al. 2017) or on both mouse and rat mPFC synaptosomal fraction (Counotte et al. 2010; Moczulska et al. 2014) over developmental ages. However, much remains to be investigated. Although proteomic analyses have the advantage of offering comprehensive unbiased results, its sensitivity is diminished when it is applied to heterogeneous brain regions such as the mPFC; therefore often it needs to be restricted to fractions such as synaptoneurosomes. Although this strategy provides important insight into the development of synaptic compartments, the rest of the cellular proteins may play an important role in the maturation of the mPFC cortex.

(C) 2018 jia et al. This article is distributed exclusively by Cold Spring Harbor Laboratory Press for the first 12 months after the full-issue publication date (see http://learnmem.cshlp.org/site/misc/terms.xhtml). After 12 months, it is available under a Creative Commons License (Attribution-NonCommercial 4.0 International), as described at http://creativecommons.org/licenses/by$\mathrm{nc} / 4.0 \%$. 
To increase the knowledge on the molecular mechanisms changing during the development of the mPFC, we focused on rat mPFC (Fig. 1) and used a biased approach aiming at surveying post-translational modification (i.e., phosphorylation), and relative concentrations of numerous biological mechanisms important for synapse maturation, plasticity, glia, and connectivity maturation. We used relative densitometric Western blot analyses to compare two early developmental ages, postnatal day 17 (PN17) and PN24 to the young adult age PN80. The two early developmental ages were chosen because they, respectively, model learning and memory associated with rapid forgetting, reflective of infantile amnesia (PN17) (Campbell and Spear 1972; Josselyn and Frankland 2012), and model a childhood age in which the rat has already acquired the ability to express long-term hippocampal-dependent memory (PN24) (Travaglia et al. 2016a).

\section{Results}

\section{Levels of immediate early genes are significantly elevated in} early development compared to adulthood

Here we determined the developmental changes of three immediate early genes (IEGs): the activity-dependent immediate-early genes c-Fos (Tischmeyer and Grimm 1999), activity-regulated-cytoskeletal-associated-protein (Arc/Arg3.1), (Bramham et al. 2008) and Zif268 (also known as EGR1 or NGFI-A) (Jones et al. 2001),

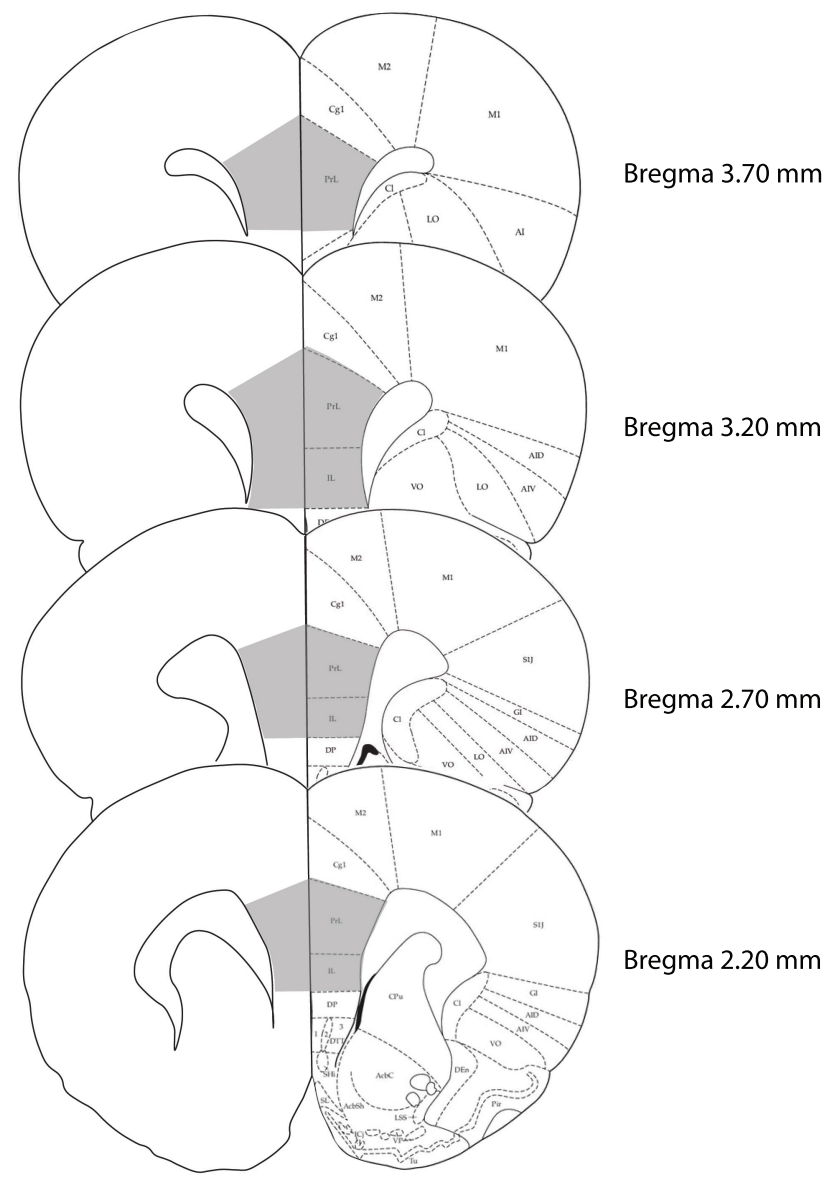

Figure 1. Rat medial prefrontal cortex coordinates (modified from Paxinos and Watson 2005) indicating the areas isolated by micropunches (in gray). which represent commonly regulated biomarkers of plasticity and behavioral responses. These IEGs, at both mRNA and protein levels, have in fact a relatively low expression in basal adult brain conditions, but are rapidly and transiently induced in response to stimulations that evoke long-term potentiation (LTP) or longterm depression (LTD), seizure, as well as behavioral experiences leading to long-term memory (Morgan et al. 1987; Cole et al. 1989; Abraham et al. 1991; Worley et al. 1993; Tischmeyer and Grimm 1999; Jones et al. 2001; Bramham et al. 2008). Whereas c-Fos and Zif268 are transcription factors, hence play a regulatory role by controlling the transcription of downstream targets that ultimately drive long-term synaptic plasticity and long-term memory formation, Arc is critical for trafficking $\alpha$-amino-3-hydroxy-5methyl-4-isoxazole propionic acid (AMPA) receptors by accelerating protein endocytosis (Lanahan and Worley 1998; Plath et al. 2006; Bramham et al. 2008; Shepherd and Bear 2011).

As shown in Figure 2, one-way ANOVA followed by NewmanKeuls post hoc tests revealed that PN17 rat mPFC had a significantly higher level of c-Fos $\left(F_{(2,20)}=4.36 ; P=0.027\right)$ compared to adult rats $(P<0.05)$ with a decreasing trend from PN17 to PN24 and an even stronger decreasing trend from PN24 to adult age, both of which, however, did not reach statistical significance $(P>$ 0.05) (Fig. 2). Both Zif268 $\left(F_{(2,21)}=25.23 ; P<0.0001\right)$ and Arc $\left(F_{(2,17)}=11.59 ; P=0.0007\right)$ were significantly higher at both PN17 and PN24 compared to adults, with no significant difference between PN17 and PN24 rats in either marker $(P>0.05)$ (Fig. 2). Thus, the mPFC at PN17 has the highest levels of Arc, c-Fos and Zif268 expression, which decrease with age and reach significantly lower levels in adulthood. These data suggest a state of higher cellular activation of the infant and early developing mPFC compared to the adult.

\section{Phosphorylation of TrkB, CREB, CaMKIll $\alpha$, and ERK is highest at PN17 and significantly decreases over development and in adulthood}

We then determined the levels of post-translational modifications that mark the activation of pathways important in synaptic plasticity, and the relative total protein levels. We investigated the phosphorylation of tropomyosin-related kinase B receptor (TrkB, also known as NTRK2), the receptor for brain-derived neurotrophic factor (BDNF). This receptor, when activated via phosphorylation at Tyr 816, regulates the phosphorylation, trafficking and expression of the N-methyl-D-aspartate receptor (NMDA) and AMPA receptors, which are critical receptors of synaptic plasticity (Martinez et al. 1998; Minichiello 2009; Andero et al. 2014). We also assessed the activation of the TrkB-downstream signal transduction pathways, namely, the phosphorylation (and total levels) of the synaptic plasticity-coupled kinases calcium/calmodulin-dependent protein kinase II alpha (CaMKII $\alpha$ ) (Lisman et al. 2002), extracellular signal-regulated kinases ERK1/2 (Sweatt 2004), and of their target transcription factor cAMP response element-binding protein (CREB) (Yin and Tully 1996; Silva et al. 1998; Mayr and Montminy 2001; Alberini 2009; Kandel 2012). The activation of these signaling and gene expression cascades is critical for long-term synaptic plasticity and memory formation. Both CaMKII $\alpha$ - and ERK-mediated signaling pathways can converge onto the activation of the transcription factor CREB, which plays a fundamental and evolutionarily conserved role in long-term plasticity and memory formation (Frank and Greenberg 1994; Yin and Tully 1996; Silva et al. 1998; Barco et al. 2003; Alberini 2009). Furthermore, disruption of the CREB pathway in the MPFC can result in fear memory inaccuracy between aversive and nonaversive stimuli in an auditory discrimination test (Vieira et al. 2014).

We specifically investigated the autophosphorylation site of CaMKII $\alpha$ at Threonine (Thr) 286 (pCamKII $\alpha$ ), which is known to 

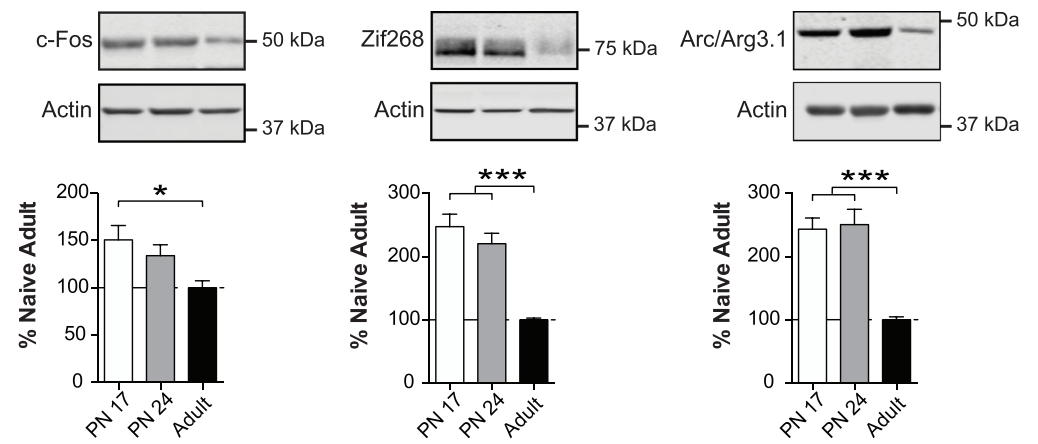

Figure 2. The levels of immediate early genes c-Fos, Zif268, and Arc are higher in early development and decrease in adulthood. Examples and densitometric Western blot analyses of mPFC total extracts from naïve rats euthanized at PN17 (white, $n=8$ ), PN24 (gray, $n=8$ ) or PN80 (adult; black, $n=4-8$ ). Data are expressed as mean percentage \pm S.E.M. of naïve adult rats. One-way ANOVA followed by Newman-Keuls post hoc tests, $\left(^{*}\right) P<0.05$, and $\left({ }^{* * *}\right) P<0.001$.
PN17 and PN24 groups compared to adults $\left(F_{(2,17)}=26.57 ; P<0.0001\right)$ (Fig. 3$)$. Hence, the ratio of pERK/ERK significantly decreased for pERK2/ERK2 from PN17 toward both PN24 and adult, with no significant difference between PN24 and adult $(P>0.05)$. Meanwhile, pERK1/ ERK1 ratio was not significantly different among the groups, despite showing a strong trend toward a decrease with age (For pERK1/ERK1: $\quad F_{(2,17)}=3.01 ; \quad P=$ 0.076; For pERK2/ERK2: $F_{(2,17)}=8.87 ; P=$ 0.002) (Fig. 3).

Together these data show that similar to the expression of IEGs, the activation of several proteins that play critical roles in synaptic plasticity, in the mPFC, is highest at PN17 and decreases with age. be critical for CaMKII $\alpha$ persistent enzymatic activation and LTP induction (Lisman et al. 2002, 2012). We also assessed the phosphorylation of ERK1 and ERK2 at Thr 202/Tyrosine (Tyr) 204 (pERK1/2), which activate ERK enzymatic activity leading to the phosphorylation and activation of downstream targets including transcription factors like CREB (Sweatt 2004; Thomas and Huganir 2004). Finally, we measured the phosphorylation at Serine (Ser) 133 of CREB (pCREB), which is critical for the recruitment of CREB coactivators that are necessary for the transcription of CREB target genes (Mayr and Montminy 2001).

As shown in Figure 3, one-way ANOVA followed by NewmanKeuls post hoc tests revealed that phosphorylated TrkB (pTrkB) at Tyr 816 was higher at PN17 compared to both PN24 and adult age $\left(F_{(2,19)}=9.04 ; P=0.0017\right.$, Fig. 3$)$ with PN24 groups showing intermediate levels. Total TrkB levels were similar in PN17 and PN24 rats, but decreased significantly in adults $\left(F_{(2,19)}=4.340 ; P=0.028\right.$, Fig. 3). Therefore, the ratio of $\mathrm{pTrkB} / \operatorname{TrkB}\left(F_{(2,19)}=7.5 ; P=0.004\right)$ significantly decreased from PN17 to both PN24 $(P<0.01)$ and adults $(P<0.05)$, while the ratio of PN24 rats was indistinguishable from that of adult rats $(P>0.05$, Fig. 3$)$.

One-way ANOVA followed by Newman-Keuls post hoc tests revealed that PN17 rats had a significantly higher level of pCREB $\left(F_{(2,20)}=9.96 ; P=0.001\right)$ compared to both PN24 and adult rats $(P<0.01)$ (Fig. 3), which had comparable levels. The level of total CREB was only significantly higher in the mPFC of PN17 compared to adults $\left(F_{(2,20)}=5.72 ; P=0.011\right)$ (Fig. 3$)$. Despite this change in total CREB level, the ratio of $\mathrm{pCREB} / \mathrm{CREB}$ in the $\mathrm{mPFC}$ remained significantly higher at PN17 compared to both PN24 and adult rats $\left(F_{(2,20)}=8.29 ; P=0.0024\right)$, without a significant difference between PN24 and adult rats $(P>0.05)$ (Fig. 3).

Furthermore, one-way ANOVA followed by Newman-Keuls post hoc tests revealed a decreasing trend, but no significant difference in the levels of pCaMKII $\alpha$ from PN17 to PN24 to adults $\left(F_{(2,13)}=2.20 ; P=0.15\right)$. Conversely, an increase in total CaMKII $\alpha$ was observed across all three age groups $\left(F_{(2,13)}=48.86 ; P<\right.$ $0.0001)$ with a significant increase seen between PN17 to PN24 $(P<0.05)$ and also between both these groups and adult rats $(P<$ $0.001)$ (Fig. 3). Despite a very strong trend, there was only a significant difference in the pCaMKII $\alpha /$ CaMKII $\alpha$ ratio $\left(F_{(2,13)}=4.22 ; P=\right.$ $0.039)$ between PN17 and adult rats $(P<0.05)$, with no difference between PN17 and PN24 or PN24 and adult rats $(P>0.05)$ (Fig. 3$)$.

There was a decreasing trend among the three increasing age groups in pERK1 $\left(F_{(2,17)}=0.74 ; P=0.50\right)$ and pERK2 $\left(F_{(2,17)}=2.49\right.$; $P=0.12)$. However, their respective total protein levels increase with age; the increase was only a trend for ERK1 $\left(F_{(2,17)}=2.197\right.$; $P=0.1416)$, but reached significance for ERK2 between both

\section{Developmental increase in GluN2A, GluAl, and GluA2 levels, with significant decrease in GluA1 phosphorylation} Next we examined the mPFC relative abundance of the N-methylD-aspartate receptor (NMDAR) subunits GluN2A and GluN2B, whose ratio in NMDARs affects the kinetics of the excitatory postsynaptic currents (EPSCs) and therefore synaptic plasticity (Sheng et al. 1994; Flint et al. 1997).

One-way ANOVA followed by Newman-Keuls post hoc tests revealed that the mPFC of PN17 rats had a significantly lower level of GluN2A $\left(F_{(2,17)}=23.26 ; P<0.0001\right)$ compared to both PN24 and adults. The opposite was true of GluN2B $\left(F_{(2,17)}=15.29 ; P=0.0002\right)$ with PN17 levels significantly higher than those of PN24 $(P<0.01)$ and adult rats $(P<0.001)$, and a significant decrease between PN24 and adult animals $(P<0.05)$ (Fig. 4$)$. The observed NMDAR subunit developmental switch in GluN2A/GluN2B ratio $\left(F_{(2,17)}=\right.$ $88.55 ; P<0.0001)$ is in line with literature reporting that postnatal cortical rat brain development is accompanied by an increase in the expression level of the GluN2A subunit, which confers different functional properties to the NMDA receptor (Sheng et al. 1994; Flint et al. 1997). In sum, there was a striking increase of the GluN2A/GluN2B ratio between PN17 to both PN24 and adult groups $(P<0.001)$, as well as a significant increase from PN24 to adults $(P<0.01)$ (Fig. 4$)$.

Because of their critical role in regulating synaptic plasticity functions, we next determined the phosphorylation and total levels of the $\alpha$-amino-3-hydroxyl-5-methyl-4-isoxazole-propionate receptor (AMPAR) subunits GluA1 and GluA2 (Song and Huganir 2002; Palmer et al. 2005). GluA1 and GluA2 are the predominant AMPA receptor subunits, controlling the majority of rapid, excitatory synaptic transmission and mediating most of the depolarizing effects of glutamate. Furthermore, activity-dependent phosphorylation of GluA1 at Ser 831 is involved in the delivery of AMPARs to synapses and single channel conductivity of the GluA1 subunit (Derkach et al. 1999; Hayashi et al. 2000), whereas its phosphorylation at Ser 845 controls synaptic maturation and strength by regulating the open probability of AMPA receptors (Barria et al. 1997).

One-way ANOVA followed by Newman-Keuls post hoc tests revealed that the mPFC of both PN17 and PN24 rats had a significantly lower level of GluA1 $\left(F_{(2,17)}=12.96 ; P=0.0004\right)$ and GluA2 $\left(F_{(2,17)}=9.905 ; P=0.0014\right)$ compared to adult rats $(P<0.001$ and $P<0.01$, respectively) (Fig. 5). No significant difference was found between PN17 and PN24 rats for either subunit $(P>0.05)$. There was a significantly higher level $\left(F_{(2,17)}=6.78 ; P=\right.$ $0.007)$ of phosphorylation of GluA1 at Ser 831 at PN17 compared to PN24 rats $(P<0.01)$, but no significant difference between PN17 

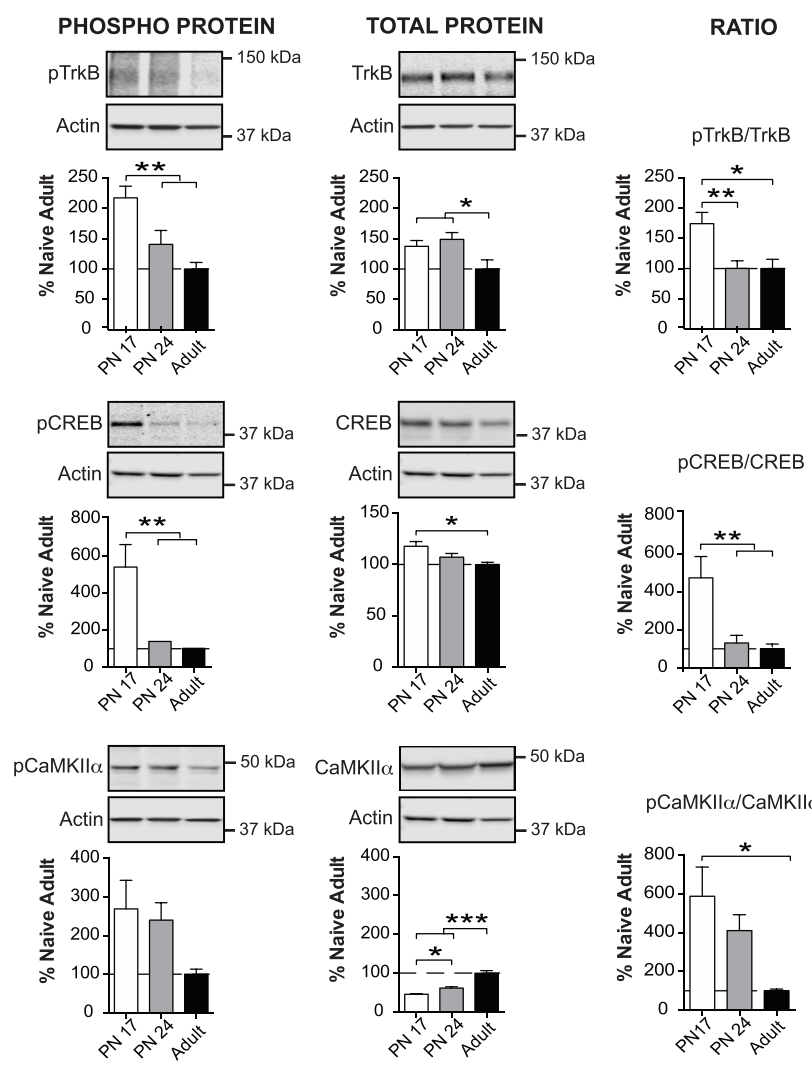

pCaMKII $\alpha /$ CaMKIl $\alpha$
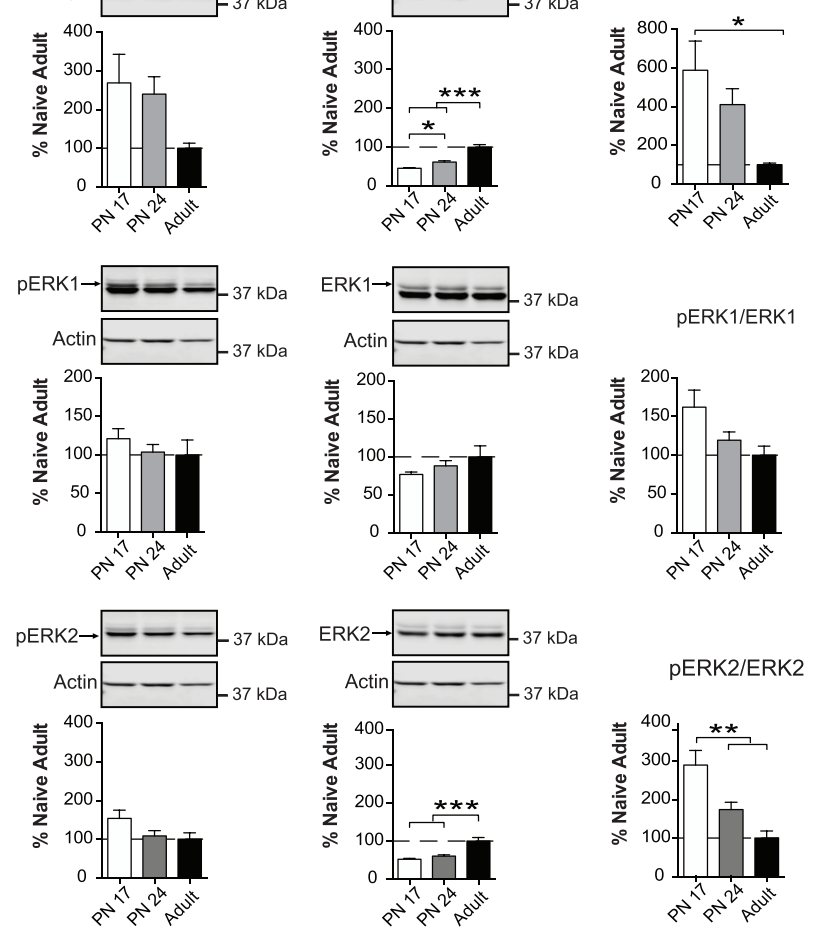

Figure 3. Significant decrease in the phosphorylation of TrkB, CREB, CamKIl $\alpha$, and ERK $1 / 2$ over development. Examples and densitometric Western blot analyses of mPFC total extracts from naïve rats euthanized at PN17 (white, $n=8$ ), PN24 (gray, $n=8$ ) or PN80 (adult; black, $n=4$ 7). Data are expressed as mean percentage \pm S.E.M. of naïve adult rats. One-way ANOVA followed by Newman-Keuls post hoc tests, $\left(^{*}\right) P<$ 0.05 , $\left(^{* \star}\right) P<0.01$, and $\left(^{* \star *}\right) P<0.001$.

or PN24 to adult rats $(P>0.05)$ (Fig. 5). The phosphorylation levels of GluA1 at Ser $845\left(F_{(2,17)}=0.89 ; P=0.44\right)$ were similar among all groups $(P>0.05)$ (Fig. 5). However, significant and substantial differences among the three age groups emerged when comparing the ratios of pGluA1 (Ser831)/GluA1 $\left[F_{(2,17)}=7.80, P=0.004\right)$; PN17 was significantly greater than PN24 $(P<0.01)$ and adult rats $(P<0.05)]$ as well as the ratio pGluA1(Ser845)/GluA1 $\left[F_{(2,17)}=\right.$
5.80; $P=0.012)$; PN 17 was significantly higher compared to both PN24 and adults $(P<0.05)]$ (Fig. 5). In both GluA1 phosphorylated/total protein ratios, there was no significant difference between PN24 and adult rats $(P>0.05)$ (Fig. 5).

Thus, despite the reduced amount of AMPA receptors in the mPFC of PN17 rats, their phosphorylations at Ser 831 and Ser 845 are significantly higher at this age group in comparison to those of PN24 and/or adult rats.

\section{Markers of excitatory and inhibitory synapse maturation increase with age}

Next, we determined the expression of pre- and postsynaptic markers that accompany excitatory or inhibitory synapse formation. As a presynaptic marker, we investigated synaptophysin (Wiedenmann and Franke 1985; Frick and Fernandez 2003; Kwon and Chapman 2011) whereas for a postsynaptic excitatory neuronal marker we analyzed postsynaptic density protein 95 (PSD-95) (Cho et al. 1992; Hunt et al. 1996; Cline 2005). The presynaptic protein synaptophysin regulates exo- and endo-cytosis of neurotransmitter vesicles (Bahler et al. 1990; Kwon and Chapman 2011), and its presence reflects the maturation of functional synapses (Wiedenmann and Franke 1985; Frick and Fernandez 2003; Kwon and Chapman 2011). On the postsynaptic side, glutamate receptors associate with several proteins that constitute a scaffold, which in turn also modulates signal transduction. Of these scaffolding proteins, PSD-95 is the most abundant member of the postsynaptic density, and is involved in assembling, clustering, and recycling AMPA receptors and exerting allosteric control over their partners (Cline 2005; Good et al. 2011). Therefore, the quantification of these two pre- and postsynaptic proteins is generally used as a measure of functional synaptic maturity.

As shown in Figure 6, one-way ANOVA followed by NewmanKeuls post hoc tests revealed that the MPFC of PN17 rats had a significantly lower level of synaptophysin $\left(F_{(2,17)}=52.97 ; P<0.0001\right)$ compared to both PN24 and adult rats $(P<0.001)$. Furthermore, PN24 rats had a significantly lower level of synaptophysin compared to that of adults $(P<0.01)$. There was also a significant increase in the level of PSD95 $\left(F_{(2,21)}=11.01 ; P=0.0005\right)$ from PN17 to both PN24 $(P<0.01)$ and adults $(P<0.001)$ without a significant difference between PN24 and adult rats $(P>0.05)$ (Fig. 6).

As correlates of inhibitory synapses, we measured levels of GAD65 and GAD67, isoforms of the enzyme that synthesizes the inhibitory neurotransmitter $\gamma$-aminobutyric acid (GABA) (Erlander et al. 1991; Bu et al. 1992; Soghomonian and Martin 1998), as well as the levels of gephyrin, which anchors the postsynaptic GABA receptor and may be involved in the plasticity of such synapses (Fritschy et al. 2008). Although GABA is the main inhibitory neurotransmitter in the adult brain, early in development (i.e., before PN10 in rats) GABAergic synaptic transmission is actually excitatory (Ben-Ari 2002). GABAergic transmission shapes excitatory/inhibitory circuitry and is necessary for neuronal development (Ben-Ari 2002; Chamberland and Topolnik 2012). GABA is synthesized by glutamic acid decarboxylase (GAD), which exists in two isoforms, GAD65 and GAD67 (Erlander et al. 1991; Bu et al. 1992; Soghomonian and Martin 1998). GAD65 is mainly concentrated in axon terminals and bound to synaptic vesicles and catalyzes GABA synthesis when there is an evoked neuronal activity. GAD67 is widely distributed throughout the cell and catalyzes GABA synthesis under resting conditions (Erlander et al. 1991; Bu et al. 1992; Soghomonian and Martin 1998). It has been shown that both mRNA and protein levels of GAD65 and GAD67 increase gradually during postnatal development (Soghomonian and Martin 1998; Frahm and Draguhn 2001; Popp et al. 2009). In agreement with these studies, one-way ANOVA followed by NewmanKeuls post hoc tests revealed that the mPFC of both PN17 and 

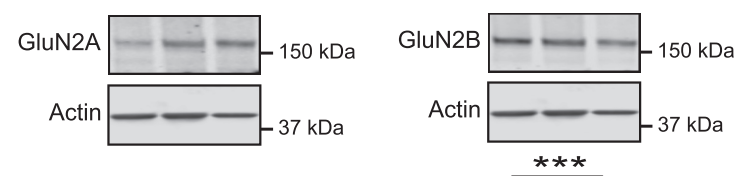

\section{GluN2A/GluN2B}
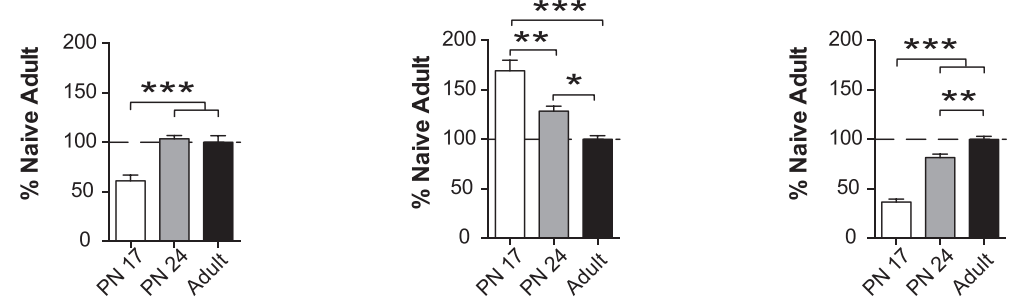

Figure 4. Significant increase in the GluN2A/GluN2B receptor subunit concentrations over development. Examples and densitometric Western blot analyses of MPFC total extracts from naiive rats euthanized at PN17 (white, $n=8$ ), PN24 (gray, $n=8$ ) or PN80 (adult; black, $n=4$ ). Data are expressed as mean percentage \pm S.E.M. of naïve adult rats. One-way ANOVA followed by Newman-Keuls post hoc tests, $\left(^{\star}\right) P<0.05,\left({ }^{* *}\right) P<0.01$, and $\left(^{* * *}\right) P<0.001$.
Furthermore, the mPFC of PN17 rats had a significantly higher level of MAP2 $\left(F_{(2,21)}=4.39 ; \quad P=0.027\right) \quad$ compared to PN24 rats $(P<0.05)$, yet there was also a significant increase from PN24 to adult rats $(P<0.05)$, resulting in similar levels of MAP2 between PN17 and adult rats $(P>0.05)$ (Fig. 7).

Next we investigated the levels of the pleiotropic kinase mechanistic target of rapamycin (mTOR) (Brown et al. 1994; Sabatini et al. 1994; Laplante and Sabatini 2012). mTOR is a master growth regulator that senses cellular oxygen, nutrition, and energy levels. It is also involved in a vast variety of metabolic functions, such as activity-dependent synaptic protein translation (Hoeffer
PN24 rats had a significantly lower level of both GAD65 $\left(F_{(2,17)}=\right.$ 67.03; $P<0.0001)$ and GAD67 $\left(F_{(2,21)}=9.49 ; P=0.0012\right)$ compared to adult rats $(P<0.001, P<0.01$, respectively) (Fig. 6). Furthermore, PN17 rat mPFC had a significantly lower level of GAD65 compared to that of PN24 $(P<0.001)$, whereas there was no such difference in the level of GAD67 $(P>0.05)$ (Fig. 6).

Gephyrin is an integral protein in the postsynaptic density, capable of self-assembly into a physical scaffold that anchors and stabilizes GABA receptors (Yu et al. 2007; Tretter et al. 2008). It also interacts with many cytoskeletal regulatory proteins and may therefore also be involved in GABA receptor trafficking to the synapse. Thus, gephyrin is a dynamic molecule that can influence inhibitory synaptic plasticity (Tyagarajan and Fritschy 2014). As shown in Figure 6, one-way ANOVA followed by NewmanKeuls post hoc tests revealed no significant difference in gephryrin levels among the three age groups $\left(F_{(2,17)}=1.15 ; P=0.34\right)$.

We concluded that there is a significant, gradual increase in the levels of both excitatory and inhibitory synapse maturation markers over postnatal development.

\section{Significant decrease in neuronal morphogenesis markers over development}

Neuronal morphogenesis has a critical role in the formation of physical networks in order to shape and support the fine structure of neuronal processes in the developing brain. Many proteins are involved in this formation, including: (i) cofilin, a ubiquitous actin-binding factor, which regulates actin filament polymerization and is activated by de-phosphorylation at Ser 3 (Yang et al. 1998; Bramham 2007); (ii) microtubule-associated protein 2 (MAP2), a neuronal protein that regulates the structure and stability of microtubules and neuronal morphogenesis (Sanchez et al. 2000) and (iii) growth associated protein 43 (GAP43), a major constituent of the growth cone that regulates cytoskeletal organization in axon terminals and in neurite formation (Aigner et al. 1995; Benowitz and Routtenberg 1997).

As shown in Figure 7, one way ANOVA followed by NewmanKeuls post hoc tests revealed no significant difference among the three age groups in GAP43 $\left(F_{(2,16)}=2.16 ; P=0.15\right)$. There was also no difference among age groups in cofilin $\left(F_{(2,20)}=1.04 ; P=0.37\right)$, but a remarkable and significantly higher level of pcofilin at PN17 $\left(F_{(2,20)}=11.33 ; P=0.0005\right)$ compared to both PN24 and adult rats $(P<0001)$. No significant difference in pcofilin was found between PN24 and adult rats, although there was a decreasing trend $(P>0.05)$. Likewise, the ratio of pcofilin/cofilin reflected a significant decrease $\left(F_{(2,20)}=11.23 ; P=0.0005\right)$ from PN17 to both PN24 $(P<0.001)$ and adults $(P<0.01)$ (Fig. 7).
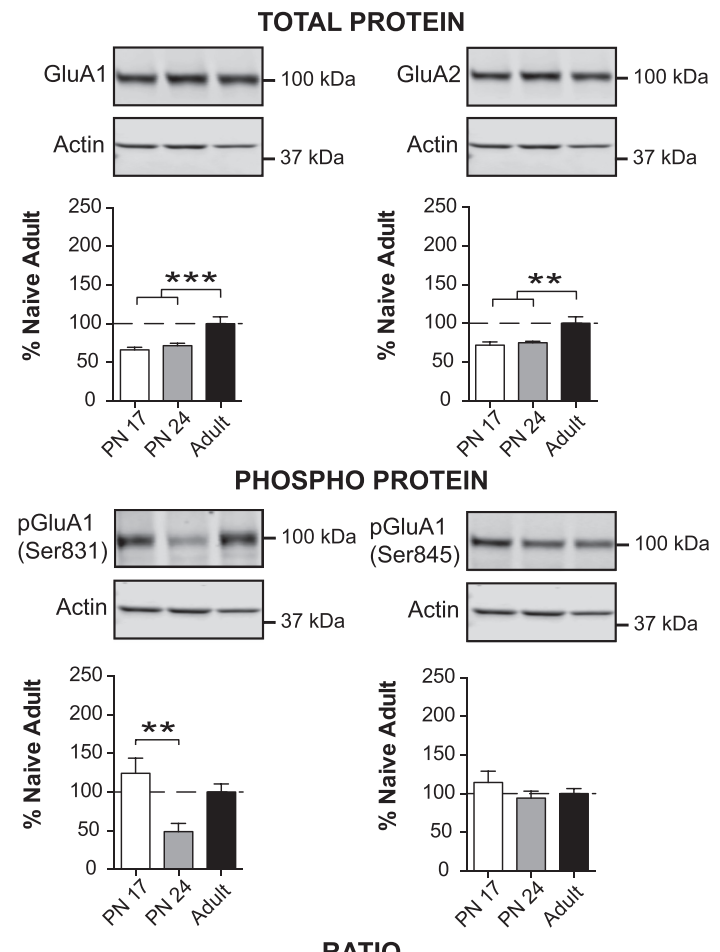

pGluA1(Ser831)/GluA1

RATIO

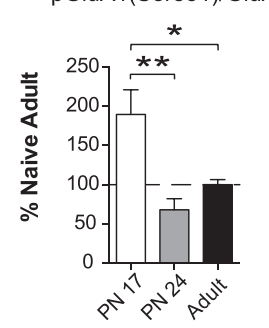

pGluA1(Ser845)/GluA1

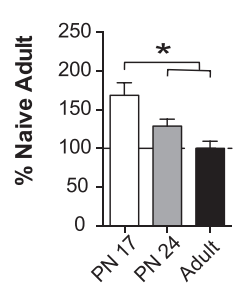

Figure 5. Significant increase in GluA1 and GluA2 AMPA receptor subunit concentration and decreasing trend in their phosphorylation over development. Examples and densitometric Western blot analyses of mPFC total extracts from naïve rats euthanized at PN17 (white, $n=$ 8), PN24 (gray, $n=8$ ) or PN80 (adult; black, $n=4$ ). Data are expressed as mean percentage \pm s.e.m. of naïve adult rats. One-way ANOVA followed by Newman-Keuls post hoc tests, $\left(^{*}\right) P<0.05$, $\left({ }^{* *}\right) P<0.01$, and $(* \star *) P<0.001$. 

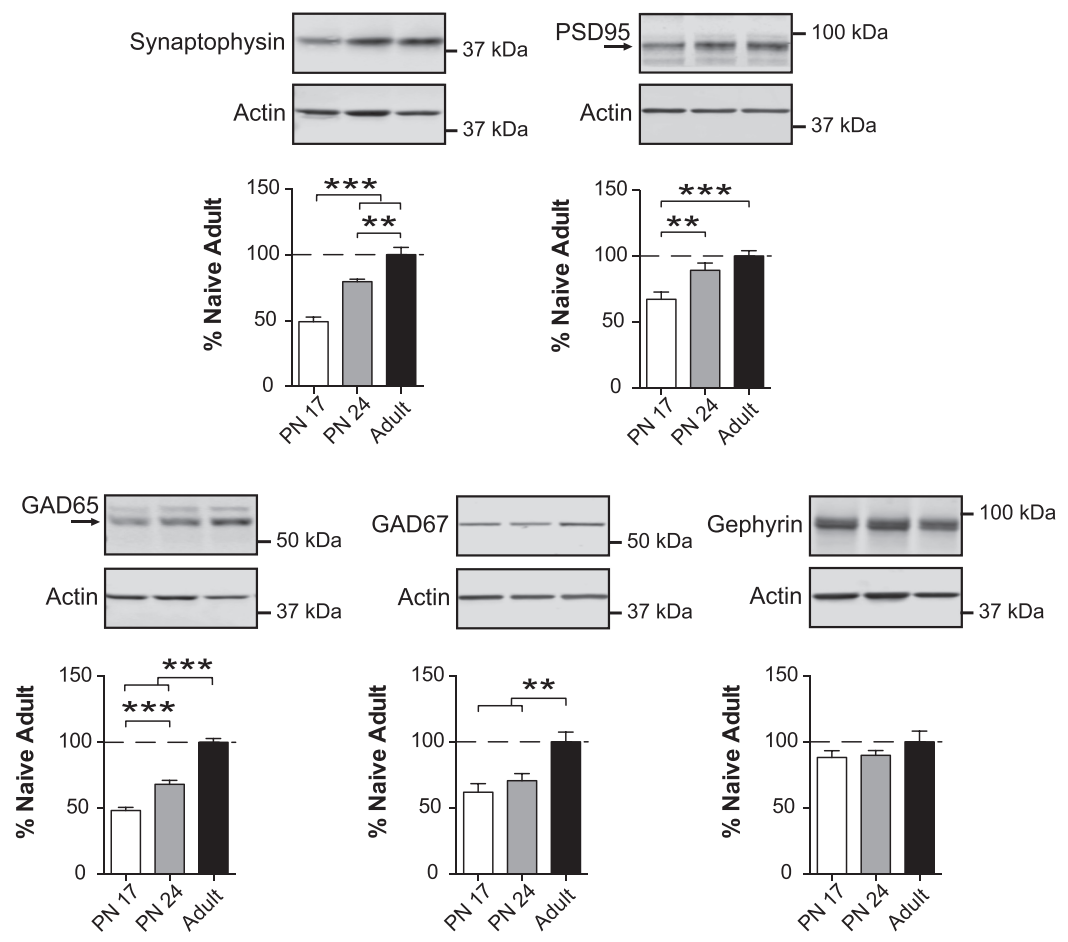

Figure 6. Markers of excitatory and inhibitory synapse maturation increase over development. Examples and densitometric Western blot analyses of mPFC total extracts from naïve rats euthanized at PN17 (white, $n=8$ ), PN24 (gray, $n=8$ ) or PN80 (adult; black, $n=4-8$ ). Data are expressed as mean percentage \pm S.E.M. of naïve adult rats. One-way ANOVA followed by Newman-Keuls post hoc tests, $\left({ }^{* *}\right) P<0.01$, and $\left.{ }^{* * *}\right) P<0.001$.

and Klann 2010; Costa-Mattioli and Monteggia 2013) autophagy, lipid synthesis, cell survival and proliferation, and oligodendrocyte differentiation and myelination (Mizushima et al. 2008; Laplante and Sabatini 2009, 2012; Narayanan et al. 2009; Wahl et al. 2014). Furthermore, mTOR, whose activation is correlated with phosphorylation at Ser 2448 (Scott et al. 1998; Nave et al. 1999; Inoki et al. 2002; Reynolds et al. 2002) also regulates growth and neuronal differentiation in the developing brain as well as the turnover of misfolded proteins in developed neurons (Graber et al. 2013). Thus, the expression and regulation of mTOR may reflect synapse and neurite functional development and maturation.

One way ANOVA followed by Newman-Keuls post hoc tests revealed no significant difference in mTOR and pmTOR levels among the three groups (mTOR: $F_{(2,17)}=3.47 ; P=0.055$; pmTOR: $F_{(2,17)}=2.74 ; P=0.093$ ) (Fig. 7). However, there was a significant decrease in the pmTOR/mTOR ratio from PN17 to PN24 $\left(F_{(2,17)}=4.59 ; P=0.026\right)$ although there was no significant difference between either PN17 or PN24 to adult rats $(P>$ 0.05) (Fig. 7).

Together, these data suggest that neuronal remodeling is significantly higher in early development and decreases with age, which is also in line with the
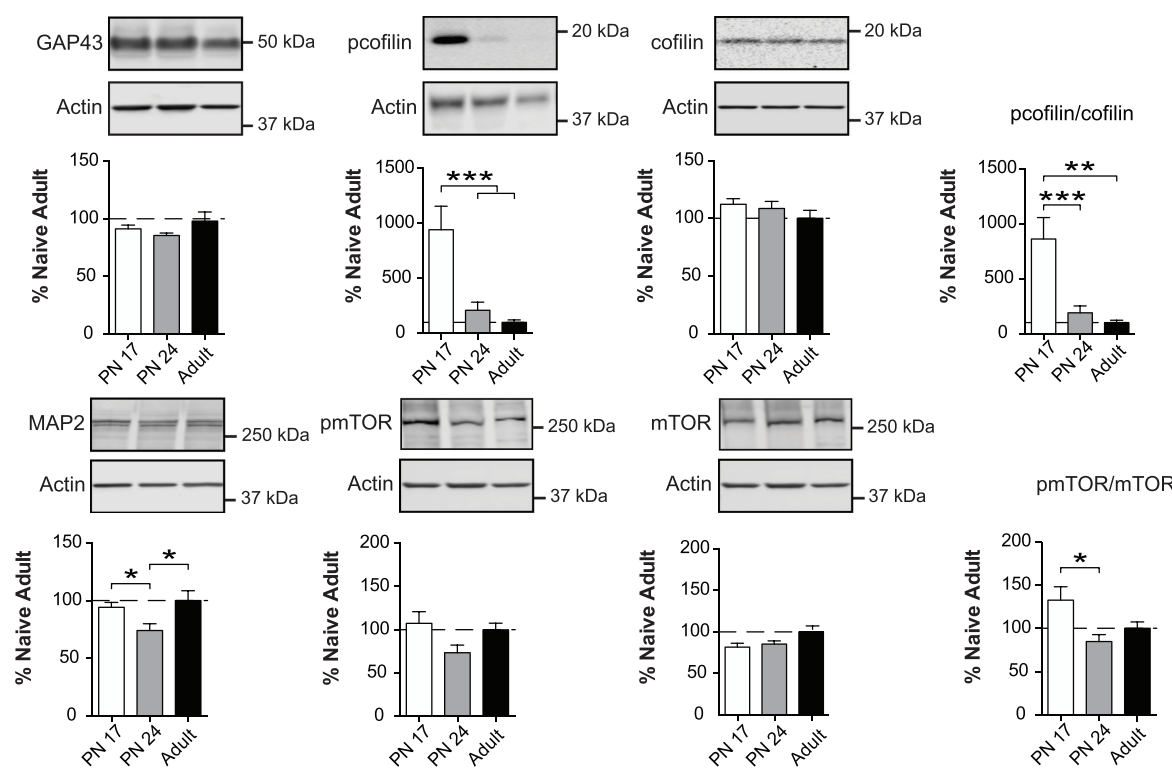

Figure 7. Changes in neurite connectivity markers over development. Examples and densitometric Western blot analyses of mPFC total extracts from naïve rats euthanized at PN17 (white, $n=8$ ), PN24 (gray, $n=8$ ) or PN80 (adult; black, $n=4$ ). Data are expressed as mean percentage \pm S.E.M. of naïve adult rats. One-way ANOVA followed by Newman-Keuls post hoc tests, $\left(^{*}\right) P<0.05,\left({ }^{* *}\right) P<0.01$, and $\left({ }^{\star * *}\right) P<0.001$. 
significantly lower level of MBP than adults $(P<0.05)$. Similarly, Nogo-R $\left(F_{(2,17)}=52.66 ; P<0.0001\right)$ also significantly increased from PN17 to both PN24 and adult $(P<0.001)$, and from PN24 to adult $(P<0.01)$ (Fig. 8). The opposite direction in expression level changes was found for Nogo-A over development $\left(F_{(2,20)}=6.827\right.$; $P=0.0055)$, as PN17 had a significantly higher level of Nogo-A than either that of PN24 $(P<0.05)$ or adult $(P<0.01)$ (Fig. 8). Interestingly, MAG $\left(F_{(2,17)}=12.83 ; P=0.0004\right)$ was significantly higher in PN24 rats compared to both PN17 $(P<0.01)$ and adults $(P<0.001)$, and although there was a decreasing trend in MAG between PN17 and adult rats, this was not statistically significant $(P>$ 0.05) (Fig. 8).

Together, these results suggest that cortical myelination drastically increases in the mPFC during postnatal development between ages PN17 and PN24.

\section{Discussion}

The assessment of changes in biological compositions of brain regions over development is critical for better understanding the maturation of their functions. Here we focused on the mPFC, a region critically involved in higher brain functions, many of which are altered in psychiatric conditions. One of these functions is learning and memory, which fundamentally contributes to the regulation and expression of most behavioral responses. We found that the levels of most synaptic and neural plasticity proteins in the mPFC compared at PN17, PN24 and PN80 (young adult) undergo massive developmental changes. The highest levels of biological changes that decrease over development are the immediate early genes (c-Fos, Arc, Zif268), plasticity markers (phosphoTrkB, phosphoCREB, phospho-ERK 1,2 and phospho-cofilin), the NMDA receptor subunit GluN2B and the phosphorylation of the AMPA receptor subunit GluA1 in Ser831 and Ser 845. The biological changes that significantly increase over development are markers of inhibitory and excitatory synapse maturation (GADs, synaptophysin and PSD95), and markers of myelination (MBP, Nogo receptor).

The significantly increased levels of IEGs, phospho-CREB, phospho-CamKII $\alpha$, phosphor-ERK ${ }_{1,2}$, at PN17 and PN24 compared to adult age suggest a significant higher degree of cellular activation in early developmental stages. We suggest that this activation occurs in response to experience. As indicated by our previous studies (Travaglia et al. 2016a), the early developing brain, although not yet functionally competent (i.e., able to express a long-term memory), is highly sensitive to learning stimuli; we believe that these stimuli, by activating molecular pathways of plasticity, including IEGs and phospho-CREB, lead to maturation of the mem- ory systems. We also believe that this activation occurs in several brain regions. This hypothesis is based on our previous studies on episodic learning in rats at PN17. Although it had been suggested that the hippocampus is not participating in forming and storing hippocampal-dependent memories in early development (Rudy and Morledge 1994; Raineki et al. 2010), our recent results on the critical role of the hippocampus in forming latent memories at PN17 is in disagreement with this hypothesis (Travaglia et al. 2016a). Based on these studies we suggested that the hippocampal memory system is highly responsive to environmental experience during this early developmental phase, which in fact frames a developmental critical period. Because in adulthood the mPFC is highly connected to the hippocampus and critically involved in processing hippocampal-dependent memories (Preston and Eichenbaum 2013), we speculate that the maturation of mPFC and hippocampus are functionally linked throughout the developmental trajectory. Thus, similarly to the dHC (Travaglia et al. 2016b) the high cellular activation at PN17 and PN24 found in the mPFC may reflect a high experience-dependent stimulation, which in fact may be also functionally linked with the hippocampus itself. We suggest that the hippocampus-mPFC system is extremely responsive to early developmental experiences. This idea is also supported by the large number of biomarkers that, as shown by our data, follow similar developmental trajectories in the two regions, such as inhibitory and excitatory synaptic maturation markers, AMPA GluA1 phosphorylation, and a switch to increased GluN2A/GluN2B.

In our previous study on the $\mathrm{dHC}$ we investigated the same proteins at the same ages using a similar approach. If we compare the kinetics of protein changes over the three ages in the two regions we found similar changes for many of the biological markers investigated. However, it also emerges that there are differential developmental changes between $\mathrm{dHC}$ and $\mathrm{mPFC}$; specifically, these are: phospho-CamKII $\alpha$, phospho-ERK ${ }_{1,2}$, MAP2, GAP43, and Nogo-R (Fig. 9). While phospho-CamKII $\alpha$ is extremely low at PN17 in the dHC compared to PN24 and PN80 (Travaglia et al. 2016b), its levels in the mPFC are highest at PN17 and significantly decrease in PN24 and adult age. Similarly, phospho-ERK ${ }_{1,2}$ levels significantly increase with age in the $\mathrm{dHC}$, but significantly decrease with age in the mPFC. We found a massive decrease in the level of MAP2 between PN17/PN24 and adult age in the dHC, whereas in the mPFC MAP2 shows similar levels at PN17 and adult age with a decrease at PN24. GAP43 does not change in the mPFC whereas it is significantly higher at PN17 and PN24 compared to adult age in the dHC. Nogo-R significantly decreases over development in the dHC but significantly increases over the same ages in the mPFC. Possible explanations for these differences include the differential cell type composition of the two regions,
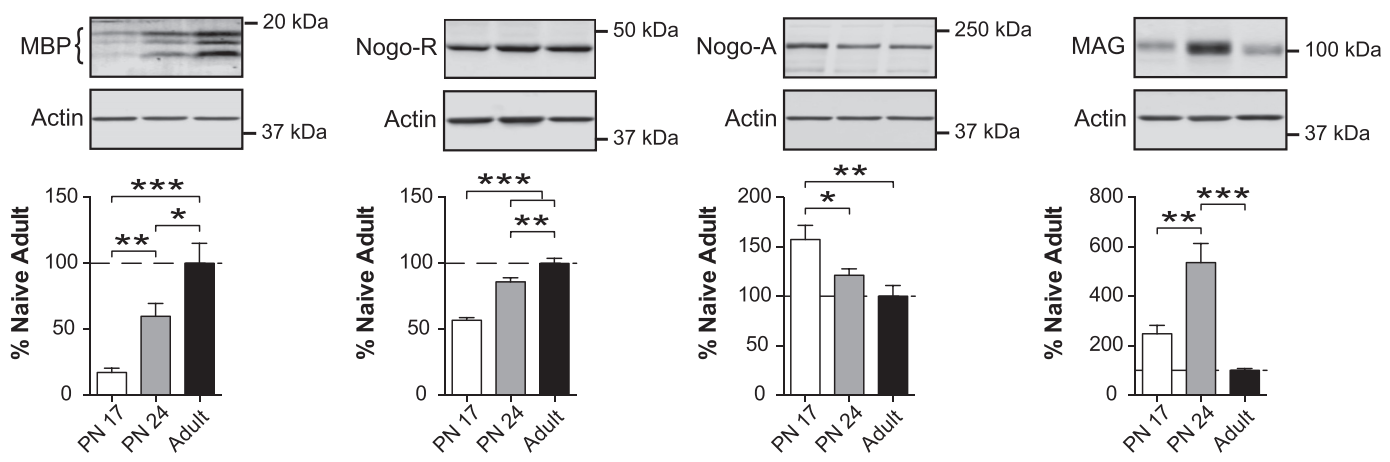

Figure 8. Changes in myelination markers over development. Examples and densitometric Western blot analyses of mPFC total extracts from naïve rats euthanized at PN17 (white, $n=8$ ), PN24 (gray, $n=8$ ) or PN80 (adult; black, $n=4-8$ ). Data are expressed as mean percentage \pm S.E.M. of naïve adult rats. One-way ANOVA followed by Newman-Keuls post hoc tests, $\left({ }^{*}\right) P<0.05,\left({ }^{* *}\right) P<0.01$, and $\left(^{* * *}\right) P<0.001$. 


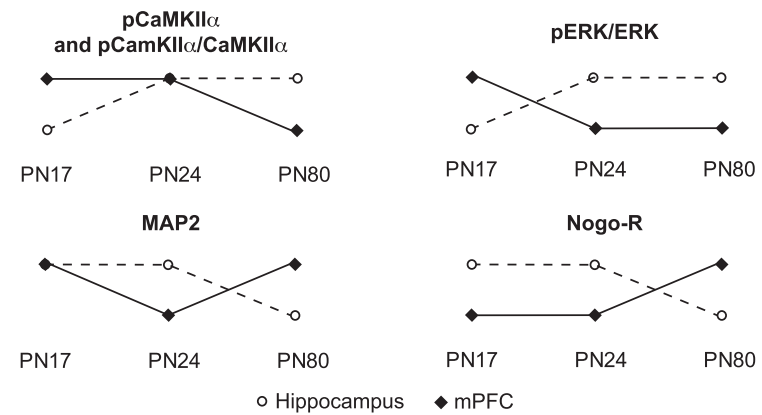

Figure 9. Differential molecular changes between hippocampus and mPFC over ages. Graphic representation of the identified temporal molecular changes occurring in the rat medial prefrontal cortex at PN17, PN24, and PN80 (adult). Data are compared with the changes identified at the same developmental changes in the dorsal hippocampus (Travaglia et al. 2016b). Only markers that show different progression over ages in the MPFC and hippocampus are shown.

their differential state of maturation and the differential structural stroma. In fact all these differences between the two regions are in structural markers, which suggest that the structural plasticity of the two regions is distinct.

The two early developmental ages compared in this study, PN17 and PN24, both of which were related to adult age (PN80), correspond to a temporal window of maturation in the ability to express episodic memories. In fact, PN17 rats show the rapid forgetting typically associated with infantile amnesia, whereas PN24 rats express long-term memories (Travaglia et al. 2016a, 2018). Biological correlations that we found significantly changed between PN17 and PN24 in the MPFC are: (i) a decrease in the markers of cell activation phospho-TrkB, phospho-CREB, phospho-GluA1-Ser 831, phospho-mTOR, and phospho-cofilin, (ii) an increase in the markers of excitatory synapses synapsin and PSD95 and the switch to higher GluN2A/GluN2B, and, finally, (iii) an increase in axonal maturation and myelination markers (increase in MBP, MAG, and Nogo-R and decrease in Nogo-A). Together, these data suggest that, whereas the brain is more highly activated in early development, a remarkable maturation occur between PN17 and PN24. Given our finding that infantile amnesia reflects a critical period of development of the hippocampal memory system (Alberini and Travaglia 2017), we propose that the significant developmental maturation occurring between PN17 and PN24 is the result of responses to experience. We also speculate that the $\mathrm{dHC}$ and the mPFC mature in a coordinated manner in response to each other's functional feedbacks. Future studies could investigate whether direct and indirect connectivity form between hippocampus and mPFC over development in response to experience.

Three final interesting observations emerging from our data that further distinguish or link the biological bases of the mPFC compared to those of the $\mathrm{dHC}$ are: first, the differential low level of changes in the mTOR and phospho-mTOR over the ages in the $\mathrm{mPFC}$, compared to the significantly higher levels in the $\mathrm{dHC}$ at both PN17 and PN24 compared to adult age. Despite these differences, in both regions the ratio phospho-mTOR/mTOR changes only slightly in the mPFC but not in the dHC. Second, the different kinetics of Nogo-A and Nogo-R in the two regions: in the mPFC Nogo-A decreases while Nogo-R increases with age, whereas in the dHC both proteins decrease over the ages. As both proteins in cooperation with others regulate axonal growth inhibition and shape CNS structure and functions, it appears that they differentially titrate these processes and therefore the capabilities of brain plasticity in the two areas. Third, like in the dHC, the axon growth-inhibitory protein MAG is massively increased at PN24 compared to the other two ages indicating a critical functional role of MAG-regulated changes in myelination around PN24 of age in the dHC-mPFC system.

In summary, our biochemical analyses show that over development the mPFC undergoes a dramatic increase in proteins that mark synaptogenesis and synapse maturation, a dramatic decrease in cell activation and a significant change in structural markers that suggest structural stabilization over time. This pattern of biological changes is in line with the idea of a higher level of activation in highly plastic, not organized biological ensembles at PN17, which rapidly matures over a week and further decreases activations while increasing order and structural organization over time. Like for the dHC, the substantial biological difference in plasticity, activity, and neural structural markers found in the mPFC at different developmental ages suggest caution in extrapolating conclusions from brain plasticity studies conducted at different ages. Synaptic plasticity studies have often used early developmental tissues to provide general conclusions about mechanisms of learning and memory. Our data suggest that, in general, the data and interpretations should be limited to the age used. It is clear from these and many other studies that the infant brain is not a small version of the adult brain, but a very distinct biological system.

\section{Materials and Methods}

\section{Animals}

Seventeen (PN17) and twenty four-day old (PN24) male and female rats were obtained from pregnant Long Evans female rats (Charles River Laboratories). Rats were housed in $30.80 \mathrm{~cm} \times 40.60 \mathrm{~cm} \times$ $22.23 \mathrm{~cm}$ plastic cages containing ALPHA-dri bedding under a 12 $\mathrm{h}$ light-dark cycle (light on at 07.00 a.m.) with food and water ad libitum. All experiments were carried out during the light cycle. The birth date was considered PNO and the litters were culled to $10-12$. Only one male and female per litter was used in any experimental condition. Rats were weaned at PN21. All procedures complied with the US National Institute of Health Guide for the Care and Use of Laboratory Animals and were approved by the New York University Animals Care Committees.

\section{Western blot analysis}

Western blot analysis was carried out as previously reported (Chen et al. 2012). Rats were euthanized and their brains were rapidly removed and frozen in isopentane. Medial prefrontal cortex (mPFC) punches were obtained with a neuro punch (19 gauge; Fine Science Tools) from frozen brains mounted on a cryostat. Samples were homogenized in ice-cold RIPA buffer $(50 \mathrm{mM}$ Tris base, $150 \mathrm{mM} \mathrm{NaCl}$, $0.1 \%$ SDS, $0.5 \%$ Na-Deoxycholate, $1 \%$ NP-40) with protease and phosphatase inhibitors [0.5 mM PMSF, 2 mM DTT, 1 mM EGTA, $2 \mathrm{mM}$ NaF, $1 \mu \mathrm{M}$ Microcystine, $1 \mathrm{mM}$ Benzamidine, $1 \mathrm{mM}$ Sodium Orthovanadate, and commercial protease and phosphatase inhibitor cocktails (Sigma-Aldrich)]. Protein concentrations were determined using the Bio-Rad protein assay (Bio-Rad Laboratories). Equal amounts of total protein $(20 \mu \mathrm{g}$ per lane) were resolved on $4 \%-20 \%$ Criterion TGX gradient gels (Bio-Rad Laboratories) and transferred to Immobilon-FL Transfer membrane (Millipore) by electroblotting. Membranes were dried, reactivated in methanol, and washed with water before they were blocked in Odyssey blocking buffer (LI-COR Bioscience, Lincoln, NE) for $1 \mathrm{~h}$ at room temperature. Membranes were then incubated with primary antibody overnight at $4^{\circ} \mathrm{C}$ in solution according to the protocol and dilution of the manufacturer. Primary antibodies included: anti-Arc (1:10000, Synaptic System, cat\# 156 003), anti-c-Fos (1:200, Millipore, cat\# PC05, Millipore), anti-Zif268 (1:1000, Cell Signaling Technology, cat\# 4153S), anti-pTrkB (Tyr816) (1:1000, Millipore, cat\# ABN1381), anti-TrkB (80E3) (1:1000, Cell Signaling Technology, cat\# 4603S), anti-pCREB(Ser133) (1:1000, Cell Signaling Technology, cat\# 9198), anti-CREB (1:1000, Cell Signaling Technology, cat\# 9104), anti-pCaMKII (Thr286) 
(1:1000, Cell Signaling Technology, cat\# 3361S), anti-CaMKII (1:1000, Millipore, cat\# 05-532), anti-pERK1/2 (pp44/42 MAPK) (Thr202/Tyr204) (1:2000, Cell Signaling Technology, cat\# 9101S), anti-ERK1/2 (p44/42 MAPK) (1:2000, Cell Signaling Technology, cat\# 4695S), anti-GluN2A (1:1000, Millipore, cat\# 7-632), anti-GluN2B (1:1000, Cell Signaling, cat\# 4212S), antiGluA1 (1:2000, Millipore, cat\# AB1504), anti-GluA2 (1:1000, UC Davis/NIH NeuroMab Facility, cat\# 75-002), anti-pAMPA Receptor GluA1 (Ser845) (1:1000, Cell Signaling Technology, cat\# 8084S), anti-pAMPA Receptor GluA1 (Ser831) (1:1000, Abcam, cat\# ab109464), anti-PSD95 (1:1000, Cell Signaling Technology, cat\# 2507S), anti-Synaptophysin (1:1000, Cell Signaling Technology, cat\# 5467), anti-GAD65 (1:1000, Millipore, cat\# ABN101), anti-GAD67 (1:1000, Millipore, cat\# AB5406), anti-Gephyrin (1:1000, Synaptic Systems, cat\# 147111), anti-growth associated protein 43 (GAP43, 1:1000, Millipore, cat\# AB5220), anti-pcofilin (Ser3) (1:1000, Abcam, cat\# ab12866), anti-cofilin (1:1000, Millipore, cat\# AB3842), antiMAP2 (1:1000, Millipore, cat\# MAB3418), anti-mTOR (1:1000, Cell Signaling Technology, cat\# 4517S), anti-pmTOR (1:1000, Cell Signaling Technology, cat\# 2971S), anti-myelin basic protein (MBP) (1:1000, Millipore, cat\# 05-675), anti-Nogo A (1:1000, Abcam, cat\# 62024), anti-Nogo Receptor (1:1000, Abcam, cat\# 26291), anti-myelin associated glycoprotein (MAG) (1:1000, Cell Signaling Technology, cat\# 9043S). The membranes were then washed in TBS with $0.1 \%$ Tween 20 (TBST) and then incubated with a species-appropriate fluorescently conjugated secondary antibody [goat anti-mouse IRDye 680LT $(1: 10,000)$ or goat anti-rabbit IRDye 800CW $(1: 10,000)$ from Li-Cor Bioscience (Lincoln, NE)] for $1 \mathrm{~h}$ at room temperature. Membranes were again washed in TBST and scanned using the Odyssey Infrared Imaging system (Li-Cor Bioscience). Data were quantified using pixel intensities with the Odyssey software (Image Studio 4.0) according to the protocols of the manufacturer (Li-Cor Bioscience). Anti-actin antibody (1:20,000, Santa Cruz Biotechnology, cat\# sc-47778) was used to co-stain all membranes and this staining was used as the relative internal loading control for all Western blots. Membranes were hybridized with different antibodies targeting different molecular weight proteins, and when appropriate, were stripped and stained with additional antibodies to target multiple proteins using the same blot. In this case, the same actin control was used for densitometric analyses of all proteins stained on the same membrane.

\section{Statistical analyses}

Data were analyzed with Prism 6 (GraphPad Software Inc.). The data were analyzed by one-way analysis of variance (ANOVA) followed by Newman-Keuls post hoc tests. The significance of the results was accepted at $P<0.05$. In all the experiments, both PN17 and PN24 females and males were included, and analyzed as a single group because statistical analyses of separate sex groups $(n=4-$ 6) showed no significant difference (unpaired two-tailed Student's $t$-test, $P>0.05$ ). Only adult (PN80) males were used in this study.

\section{Acknowledgments}

This work was supported by MH065635 grant to C.M.A.

\section{References}

Abraham WC, Dragunow M, Tate WP. 1991. The role of immediate early genes in the stabilization of long-term potentiation. Mol Neurobiol 5: 297-314.

Agoglia AE, Holstein SE, Small AT, Spanos M, Burrus BM, Hodge CW. 2017. Comparison of the adolescent and adult mouse prefrontal cortex proteome. PLoS One 12: e0178391.

Aigner L, Arber S, Kapfhammer JP, Laux T, Schneider C, Botteri F, Brenner HR, Caroni P. 1995. Overexpression of the neural growthassociated protein GAP-43 induces nerve sprouting in the adult nervous system of transgenic mice. Cell 83: 269-278.

Alberini CM. 2009. Transcription factors in long-term memory and synaptic plasticity. Physiol Rev 89: 121-145.
Alberini CM, Travaglia A. 2017. Infantile amnesia: a critical period of learning to learn and remember. J Neurosci 37: 5783-5795.

Andero R, Choi DC, Ressler KJ. 2014. BDNF-TrkB receptor regulation of distributed adult neural plasticity, memory formation, and psychiatric disorders. Prog Mol Biol Transl Sci 122: 169-192.

Arnsten AF, Wang MJ, Paspalas CD. 2012. Neuromodulation of thought: flexibilities and vulnerabilities in prefrontal cortical network synapses. Neuron 76: 223-239.

Bahler M, Benfenati F, Valtorta F, Greengard P. 1990. The synapsins and the regulation of synaptic function. Bioessays 12: 259-263.

Barco A, Pittenger C, Kandel ER. 2003. CREB, memory enhancement and the treatment of memory disorders: promises, pitfalls and prospects. Expert Opin Ther Targets 7: 101-114.

Barria A, Muller D, Derkach V, Griffith LC, Soderling TR. 1997. Regulatory phosphorylation of AMPA-type glutamate receptors by CaM-KII during long-term potentiation. Science 276: 2042-2045.

Ben-Ari Y. 2002. Excitatory actions of gaba during development: the nature of the nurture. Nat Rev Neurosci 3: 728-739.

Benowitz LI, Routtenberg A. 1997. GAP-43: an intrinsic determinant of neuronal development and plasticity. Trends Neurosci 20: 84-91.

Boggs JM. 2006. Myelin basic protein: a multifunctional protein. Cell Mol Life Sci 63: 1945-1961.

Bramham CR. 2007. Control of synaptic consolidation in the dentate gyrus: mechanisms, functions, and therapeutic implications. Prog Brain Res 163: $453-471$.

Bramham CR, Worley PF, Moore MJ, Guzowski JF. 2008. The immediate early gene arc/arg3.1: regulation, mechanisms, and function. J Neurosci 28: $11760-11767$.

Brown EJ, Albers MW, Shin TB, Ichikawa K, Keith CT, Lane WS, Schreiber SL. 1994. A mammalian protein targeted by G1-arresting rapamycinreceptor complex. Nature 369: 756-758.

Bu DF, Erlander MG, Hitz BC, Tillakaratne NJ, Kaufman DL, WagnerMcPherson CB, Evans GA, Tobin AJ. 1992. Two human glutamate decarboxylases, 65-kDa GAD and 67-kDa GAD, are each encoded by a single gene. Proc Natl Acad Sci 89: 2115-2119.

Campbell BA, Spear NE. 1972. Ontogeny of memory. Psychol Rev 79: 215-236.

Chamberland S, Topolnik L. 2012. Inhibitory control of hippocampal inhibitory neurons. Front Neurosci 6: 165.

Chen DY, Bambah-Mukku D, Pollonini G, Alberini CM. 2012. Glucocorticoid receptors recruit the CaMKII $\alpha$-BDNF-CREB pathways to mediate memory consolidation. Nat Neurosci 15: 1707-1714.

Cho KO, Hunt CA, Kennedy MB. 1992. The rat brain postsynaptic density fraction contains a homolog of the Drosophila discs-large tumor suppressor protein. Neuron 9: 929-942.

Cline H. 2005. Synaptogenesis: a balancing act between excitation and inhibition. Curr Biol 15: R203-R205.

Cole AJ, Saffen DW, Baraban JM, Worley PF. 1989. Rapid increase of an immediate early gene messenger RNA in hippocampal neurons by synaptic NMDA receptor activation. Nature 340: 474-476.

Costa-Mattioli M, Monteggia LM. 2013. mTOR complexes in neurodevelopmental and neuropsychiatric disorders. Nat Neurosci 16: 1537-1543.

Counotte DS, Li KW, Wortel J, Gouwenberg Y, Van Der Schors RC, Smit AB, Spijker S. 2010. Changes in molecular composition of rat medial prefrontal cortex synapses during adolescent development. Eur J Neurosci 32: 1452-1460.

Derkach V, Barria A, Soderling TR. 1999. $\mathrm{Ca}^{2+} /$ calmodulin-kinase II enhances channel conductance of $\alpha$-amino-3-hydroxy-5-methyl-4isoxazolepropionate type glutamate receptors. Proc Natl Acad Sci 96: 3269-3274.

Eichenbaum H. 2017. Prefrontal-hippocampal interactions in episodic memory. Nat Rev Neurosci 18: 547-558.

Erlander MG, Tillakaratne NJ, Feldblum S, Patel N, Tobin AJ. 1991. Two genes encode distinct glutamate decarboxylases. Neuron 7: 91-100.

Euston DR, Gruber AJ, McNaughton BL. 2012. The role of medial prefrontal cortex in memory and decision making. Neuron 76: 1057-1070.

Eylar EH, Brostoff S, Hashim G, Caccam J, Burnett P. 1971. Basic A1 protein of the myelin membrane. The complete amino acid sequence. J Biol Chem 246: 5770-5784.

Flint AC, Maisch US, Weishaupt JH, Kriegstein AR, Monyer H. 1997. NR2A subunit expression shortens NMDA receptor synaptic currents in developing neocortex. J Neurosci 17: 2469-2476.

Fournier AE, GrandPre T, Strittmatter SM. 2001. Identification of a receptor mediating Nogo-66 inhibition of axonal regeneration. Nature 409: 341-346.

Frahm C, Draguhn A. 2001. GAD and GABA transporter (GAT-1) mRNA expression in the developing rat hippocampus. Brain Res Dev Brain Res 132: $1-13$.

Frank DA, Greenberg ME. 1994. CREB: a mediator of long-term memory from mollusks to mammals. Cell 79: 5-8. 
Frankland PW, Bontempi B. 2005. The organization of recent and remote memories. Nat Rev Neurosci 6: 119-130.

Frick KM, Fernandez SM. 2003. Enrichment enhances spatial memory and increases synaptophysin levels in aged female mice. Neurobiol Aging 24: 615-626.

Fritschy JM, Harvey RJ, Schwarz G. 2008. Gephyrin: where do we stand, where do we go? Trends in Neurosci 31: 257-264.

Giustino TF, Maren S. 2018. Noradrenergic modulation of fear conditioning and extinction. Front Behav Neurosci 12: 43.

Gonzalez-Lozano MA, Klemmer P, Gebuis T, Hassan C, van Nierop P, van Kesteren RE, Smit AB, Li KW. 2016. Dynamics of the mouse brain cortical synaptic proteome during postnatal brain development. Sci Rep 6: 35456.

Good MC, Zalatan JG, Lim WA. 2011. Scaffold proteins: hubs for controlling the flow of cellular information. Science 332: $680-686$.

Graber TE, McCamphill PK, Sossin WS. 2013. A recollection of mTOR signaling in learning and memory. Learn Mem 20: 518-530.

Harauz G, Boggs JM. 2013. Myelin management by the 18.5-kDa and 21.5$\mathrm{kDa}$ classic myelin basic protein isoforms. J Neurochem 125: 334-361.

Hayashi Y, Shi SH, Esteban JA, Piccini A, Poncer JC, Malinow R. 2000. Driving AMPA receptors into synapses by LTP and CaMKII: requirement for GluR1 and PDZ domain interaction. Science 287: 2262-2267.

Hoeffer CA, Klann E. 2010. mTOR signaling: at the crossroads of plasticity, memory and disease. Trends Neurosci 33: 67-75.

Hunt CA, Schenker LJ, Kennedy MB. 1996. PSD-95 is associated with the postsynaptic density and not with the presynaptic membrane at forebrain synapses. J Neurosci 16: 1380-1388.

Hyman JM, Hasselmo ME, Seamans JK. 2011. What is the functional relevance of prefrontal cortex entrainment to hippocampal theta rhythms. Front Neurosci 5: 24.

Inoki K, Li Y, Zhu T, Wu J, Guan KL. 2002. TSC2 is phosphorylated and inhibited by Akt and suppresses mTOR signalling. Nat Cell Biol 4: 648-657.

Jones MW, Errington ML, French PJ, Fine A, Bliss TV, Garel S, Charnay P, Bozon B, Laroche S, Davis S. 2001. A requirement for the immediate early gene Zif268 in the expression of late LTP and long-term memories. Nat Neurosci 4: 289-296.

Josselyn SA, Frankland PW. 2012. Infantile amnesia: a neurogenic hypothesis. Learn Mem 19: 423-433.

Kandel ER. 2012. The molecular biology of memory: cAMP, PKA, CRE, CREB-1, CREB-2, and CPEB. Mol Brain 5: 14.

Kwon SE, Chapman ER. 2011. Synaptophysin regulates the kinetics of synaptic vesicle endocytosis in central neurons. Neuron 70: 847-854.

Laeremans A, Van de Plas B, Clerens S, Van den Bergh G, Arckens L, Hu TT. 2013. Protein expression dynamics during postnatal mouse brain development. J Exp Neurosci 7: 61-74.

Lanahan A, Worley P. 1998. Immediate-early genes and synaptic function. Neurobiol Learn Mem 70: 37-43.

Laplante M, Sabatini DM. 2009. mTOR signaling at a glance. J Cell Sci 122: 3589-3594.

Laplante M, Sabatini DM. 2012. mTOR signaling in growth control and disease. Cell 149: 274-293.

Lisman J, Schulman H, Cline H. 2002. The molecular basis of CaMKII function in synaptic and behavioural memory. Nat Rev Neurosci 3: 175-190.

Lisman J, Yasuda R, Raghavachari S. 2012. Mechanisms of CaMKII action in long-term potentiation. Nat Rev Neurosci 13: 169-182.

Martinez A, Alcantara S, Borrell V, Del Rio JA, Blasi J, Otal R, Campos N, Boronat A, Barbacid M, Silos-Santiago I, et al. 1998. TrkB and TrkC signaling are required for maturation and synaptogenesis of hippocampal connections. J Neurosci 18: 7336-7350.

Mayr B, Montminy M. 2001. Transcriptional regulation by the phosphorylation-dependent factor CREB. Nat Rev Mol Cell Biol 2: 599-609.

McKerracher L, David S, Jackson DL, Kottis V, Dunn RJ, Braun PE. 1994. Identification of myelin-associated glycoprotein as a major myelinderived inhibitor of neurite growth. Neuron 13: 805-811.

Minichiello L. 2009. TrkB signalling pathways in LTP and learning. Nat Rev Neurosci 10: 850-860.

Mizushima N, Levine B, Cuervo AM, Klionsky DJ. 2008. Autophagy fights disease through cellular self-digestion. Nature 451: 1069-1075.

Moczulska KE, Pichler P, Schutzbier M, Schleiffer A, Rumpel S, Mechtler K. 2014. Deep and precise quantification of the mouse synaptosomal proteome reveals substantial remodeling during postnatal maturation. $J$ Proteome Res 13: 4310-4124.

Morgan JI, Cohen DR, Hempstead JL, Curran T. 1987. Mapping patterns of c-fos expression in the central nervous system after seizure. Science 237: 192-197.

Mukhopadhyay G, Doherty P, Walsh FS, Crocker PR, Filbin MT. 1994. A novel role for myelin-associated glycoprotein as an inhibitor of axonal regeneration. Neuron 13: 757-767.
Narayanan SP, Flores AI, Wang F, Macklin WB. 2009. Akt signals through the mammalian target of rapamycin pathway to regulate CNS myelination. $J$ Neurosci 29: 6860-6870.

Nave BT, Ouwens M, Withers DJ, Alessi DR, Shepherd PR. 1999. Mammalian target of rapamycin is a direct target for protein kinase B: identification of a convergence point for opposing effects of insulin and amino-acid deficiency on protein translation. Biochem J 344: 427-431.

Palmer CL, Cotton L, Henley JM. 2005. The molecular pharmacology and cell biology of $\alpha$-amino-3-hydroxy-5-methyl-4-isoxazolepropionic acid receptors. Pharmacol Rev 57: 253-277.

Paxinos G, Watson C. 2005. The rat brain in stereotaxic coordinates. Compact 6th ed. Academic, New York.

Penagos H, Varela C, Wilson MA. 2017. Oscillations, neural computations and learning during wake and sleep. Curr Opin Neurobiol 44: $193-201$.

Plath N, Ohana O, Dammermann B, Errington ML, Schmitz D, Gross C, Mao X, Engelsberg A, Mahlke C, Welzl H, et al. 2006. Arc/Arg3.1 is essential for the consolidation of synaptic plasticity and memories. Neuron 52: 437-444.

Popp A, Urbach A, Witte OW, Frahm C. 2009. Adult and embryonic GAD transcripts are spatiotemporally regulated during postnatal development in the rat brain. PLoS One 4: e4371.

Preston AR, Eichenbaum W. 2013. Interplay of hippocampus and prefrontal cortex in memory. Curr Biol 23: R764-R773.

Quarles RH. 2007. Myelin-associated glycoprotein (MAG): past, present and beyond. J Neurochem 100: 1431-1448.

Raineki C, Holman PJ, Debiec J, Bugg M, Beasley A, Sullivan RM. 2010. Functional emergence of the hippocampus in context fear learning in infant rats. Hippocampus 20: 1037-1046.

Readhead C, Takasashi N, Shine HD, Saavedra R, Sidman R, Hood L. 1990. Role of myelin basic protein in the formation of central nervous system myelin. Ann N Y Acad Sci 605: 280-285.

Reynolds THt, Bodine SC, Lawrence JC Jr. 2002. Control of Ser2448 phosphorylation in the mammalian target of rapamycin by insulin and skeletal muscle load. J Biol Chem 277: 17657-17662.

Rudy JW, Morledge P. 1994. Ontogeny of contextual fear conditioning in rats: implications for consolidation, infantile amnesia, and hippocampal system function. Behav Neurosci 108: 227-234.

Rushworth MF, Noonan MP, Boorman ED, Walton ME, Behrens TE. 2011. Frontal cortex and reward-guided learning and decision-making. Neuron 70: $1054-1069$.

Sabatini DM, Erdjument-Bromage H, Lui M, Tempst P, Snyder SH. 1994. RAFT1: a mammalian protein that binds to FKBP12 in a rapamycin-dependent fashion and is homologous to yeast TORs. Cell 78: $35-43$.

Sanchez C, Diaz-Nido J, Avila J. 2000. Phosphorylation of microtubuleassociated protein 2 (MAP2) and its relevance for the regulation of the neuronal cytoskeleton function. Prog Neurobiol 61: 133-168.

Schubert D, Martens GJM, Kolk SM. 2015. Molecular underpinnings of prefrontal cortex development in rodents provide insights into the etiology of neurodevelopmental disorders. Mol Psychiatry 20: 795-809.

Scott PH, Brunn GJ, Kohn AD, Roth RA, Lawrence JC Jr. 1998. Evidence of insulin-stimulated phosphorylation and activation of the mammalian target of rapamycin mediated by a protein kinase B signaling pathway. Proc Natl Acad Sci 95: 7772-7777.

Sheng M, Cummings J, Roldan LA, Jan YN, Jan LY. 1994. Changing subunit composition of heteromeric NMDA receptors during development of rat cortex. Nature 368: 144-147.

Shepherd JD, Bear MF. 2011. New views of arc. Nat Neurosci 14: 279-284.

Silva AJ, Kogan JH, Frankland PW, Kida S. 1998. CREB and memory. Аnnu Rev Neurosci 21: 127-148.

Soghomonian JJ, Martin DL. 1998. Two isoforms of glutamate decarboxylase: why? Trends Pharmacol Sci 19: 500-505.

Song I, Huganir RL. 2002. Regulation of AMPA receptors during synaptic plasticity. Trends Neurosci 25: 578-588.

Squire LR, Dede AJ. 2015. Conscious and unconscious memory systems. Cold Spring Harb Perspect Biol 7: a021667.

Sweatt JD. 2004. Mitogen-activated protein kinases in synaptic plasticity and memory. Curr Opin Neurobiol 14: 311-317.

Thomas GM, Huganir RL. 2004. MAPK cascade signalling and synaptic plasticity. Nat Rev Neurosci 5: 173-183.

Tischmeyer W, Grimm R. 1999. Activation of immediate early genes and memory formation. Cellular Mol Life Sci 55: 564-574.

Travaglia A, Bisaz R, Sweet ES, Blitzer RD, Alberini CM. 2016a. Infantile amnesia reflects a developmental critical period for hippocampal learning. Nat Neurosci 19: 1225-1233.

Travaglia A, Bisaz R, Cruz E, Alberini CM. 2016b. Developmental changes in plasticity, synaptic, glia and connectivity protein levels in rat dorsal hippocampus. Neurobiol Learn Mem 135: 125-138. 
Travaglia A, Steinmetz AB, Miranda JM, Alberini CM. 2018. Mechanisms of critical period in the hippocampus underlie object location learning and memory in infant rats. Learn Mem 25: 176-182.

Tretter V, Jacob TC, Mukherjee J, Fritschy JM, Pangalos MN, Moss SJ. 2008. The clustering of $\mathrm{GABA}(\mathrm{A})$ receptor subtypes at inhibitory synapses is facilitated via the direct binding of receptor $\alpha 2$ subunits to gephyrin. $J$ Neurosci 28: 1356-1365.

Tyagarajan SK, Fritschy JM. 2014. Gephyrin: a master regulator of neuronal function? Nat Rev Neurosci 15: 141-156.

Vieira PA, Lovelace JW, Corches A, Rashid AJ, Josselyn SA, Korzus E. 2014. Prefrontal consolidation supports the attainment of fear memory accuracy. Learn Mem 21: 394-405.

Wahl SE, McLane LE, Bercury KK, Macklin WB, Wood TL. 2014. Mammalian target of rapamycin promotes oligodendrocyte differentiation, initiation and extent of CNS myelination. J Neurosci 34: 4453-4465.

Wiedenmann B, Franke WW. 1985. Identification and localization of synaptophysin, an integral membrane glycoprotein of $\mathrm{Mr} 38,000$ characteristic of presynaptic vesicles. Cell 41: 1017-1028.
Worley PF, Bhat RV, Baraban JM, Erickson CA, McNaughton BL, Barnes CA. 1993. Thresholds for synaptic activation of transcription factors in hippocampus: correlation with long-term enhancement. J Neurosci 13: 4776-4786.

Yang N, Higuchi O, Ohashi K, Nagata K, Wada A, Kangawa K, Nishida E, Mizuno K. 1998. Cofilin phosphorylation by LIM-kinase 1 and its role in Rac-mediated actin reorganization. Nature 393: 809-812.

Ye X, Kapeller-Libermann D, Travaglia A, Inda MC, Alberini CM. 2017. Direct dorsal hippocampal-prelimbic cortex connections strengthen fear memories. Nat Neurosci 20: 52-61.

Yin JC, Tully T. 1996. CREB and the formation of long-term memory. Curr Opin Neurobiol 6: 264-268.

Yu W, Jiang M, Miralles CP, Li RW, Chen G, de Blas AL. 2007. Gephyrin clustering is required for the stability of GABAergic synapses. Mol Cell Neurosci 36: 484-500.

Received April 27, 2018; accepted in revised form July 6, 2018. 


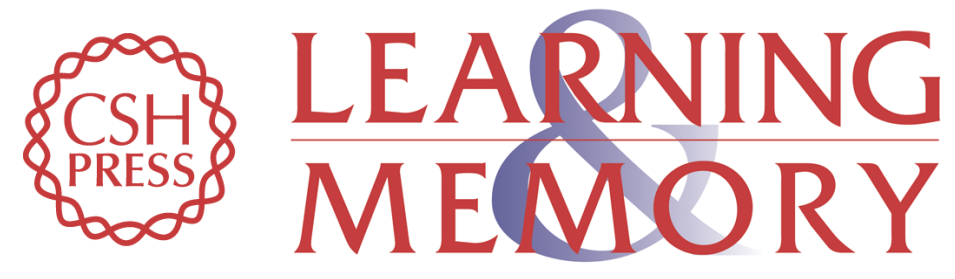

\section{Developmental changes in plasticity, synaptic, glia, and connectivity protein levels in rat medial prefrontal cortex}

Margaret Jia, Alessio Travaglia, Gabriella Pollonini, et al.

Learn. Mem. 2018, 25:

Access the most recent version at doi:10.1101/Im.047753.118

\begin{aligned} & \hline References $\begin{array}{l}\text { This article cites } 104 \text { articles, } 26 \text { of which can be accessed free at: } \\ \text { http://learnmem.cshlp.org/content/25/10/533.full.html\#ref-list-1 }\end{array} \\ & \begin{array}{r}\text { Creative } \\ \text { Commons } \\ \text { License }\end{array} \begin{array}{l}\text { This article is distributed exclusively by Cold Spring Harbor Laboratory Press for the } \\ \text { first } 12 \text { months after the full-issue publication date (see } \\ \text { http://learnmem.cshlp.org/site/misc/terms.xhtml). After } 12 \text { months, it is available under } \\ \text { a Creative Commons License (Attribution-NonCommercial } 4.0 \text { International), as } \\ \text { described at http://creativecommons.org/licenses/by-nc/4.0/. }\end{array} \\ & \begin{array}{c}\text { Receive free email alerts when new articles cite this article - sign up in the box at the } \\ \text { top right corner of the article or click here. }\end{array} \\ & \begin{array}{l}\text { Service } \\ \text { terting }\end{array}\end{aligned}$

